\title{
Guest Opinion: Undergraduate Research at the University of Northern lowa
}

\author{
Joel K. Haack, Dean \\ College of Natural Sciences \\ University of Northern lowa \\ Cedar Falls, lowa 50614-0181 USA
}

Undergraduate research has received at least lip service from almost all institutions, for at least the best of its students. In fact, I believe that there is no substitute for it for any undergraduate science major (and I will be using "science" as shorthand for all the STEM disciplines). A recent study by SRI International, reported in a recent issue of Science, concludes that the key element of successful undergraduate research experiences is the "inculcation of enthusiasm," with mentors who themselves "are able to combine enthusiasm with interpersonal, organizational, and research skills." It recommends that students have these experiences as soon as possible in their careers. $^{1}$

At the University of Northern lowa (UNI), we encourage-and, in some programs, require-undergraduate students to pursue research. Our faculty members are here because of their interest and eagerness to work with students. There would seem to be nothing quite equivalent to research opportunities in a standard classroom-based curriculum. In many classes, students learn the results of scientific disciplines, but have little opportunity to do science themselves. In other classes, instructors have carefully planned assignments to give their students some sense of what it means to do science, to participate in the disciplinary community, but these projects typically have a fixed time frame, often do not begin with questions they have generated, and may have limited opportunities to share what is learned with

${ }^{1}$ S. H. Russell, M. P. Hancock, J. McCullough, Science 316, 549 (2006). their disciplinary community. It seems to me that, only in a full-scale research opportunity will students be able to experience the entire scientific process.

At UNI, students experience the entire process of research as it typically occurs - ask a question or formulate a project, apply for support for required funds to pursue the project, carry out the research, then make a public presentation of the results. Our College of Natural Sciences offers undergraduate students an opportunity twice each year to apply for $\$ 500$ grants to support their research, resulting in an investment by the college of perhaps $\$ 40,000$ each year in this part of their education. Support is provided for the students to attend national, state, or disciplinary conferences at which they present their results. For others, presentation of the results occurs at the local level; there are several research poster presentations by students throughout the year on our campus.

Of course, the American Journal of Undergraduate Research makes it possible for students to experience the final step in a research project that a typical scientist would take, offering the results of their research in a refereed journal publication. I am grateful to the General Editor, Dr. Cliff Chancey, and to the disciplinary editors for their dedication to this journal and the education that students receive through its publication.

Joel Haack is Professor of Mathematics and Dean of the College of Natural Sciences at the University of Northern lowa (Cedar Falls, lowa, USA). He received a BA, two MS degrees, and a PhD from the University of lowa (lowa City, lowa, USA). Dr. Haack has taught at UNI since 1991. 